\title{
Conservation Biology as an Academic Discipline: Novosibirsk State University's Master's Degree Program Experience
}

\author{
Alexander Dubynin* \\ Central Siberian Botanical Garden SB RAS, 630090 Novosibirsk, Russia
}

\begin{abstract}
A reduction in the planet's biodiversity requires an active response by politicians, environmental activists, and scientists. Modern biological education should provide an opportunity to acquire the knowledge and skills necessary to solve complex tasks targeted at preserving and restoring vulnerable species habitats and ecosystems. Students study conservation biology at many universities around the world with this as their goal. For the first time in Russia, a Master's Conservation Biology course for biology students was developed and tested at Novosibirsk State University. This primer course (108 hours) includes lectures, discussions, excursions, elements of gamification, combines auditorium and online classes, uses social networks for additional communication with students, and experienced practitioners. The course has been highly rated by students and can be expanded to include a larger audience.
\end{abstract}

\section{Introduction}

Conservation Biology is a relatively young field of interdisciplinary research that has emerged at the intersection of biology, genetics, environmental management, and nature protection. The massive destruction of forests, especially tropical ones, the acceleration of species extinction, and the reduction of genetic diversity within species have prompted the scientific community to formulate the need to bridge the gap between ecology theory and evolutionary genetics on the one hand, and environmental policies and practices, on the other. The definition, goals, and objectives of Conservation Biology were established in 1978 at The First International Conference on Research in Conservation Biology by Bruce Wilcox and Michael Soulé [1].

Conservation Biology objectives, despite their generally applied nature, are not limited by the borders of countries and are supranational. The ability to identify and critically understand problems related to the conservation of biological diversity and vulnerable species, and the development of projects to protect and restore vulnerable species and ecosystems have become sought-after professional skills for biologists around the world [2].

\footnotetext{
* Corresponding author: adubynin@yandex.ru
} 
In a number of countries, this discipline is the basis for annual educational programs as well as a Master's Program specialization. For example, in the United States of America hundreds of students receive a Master's Degree in Conservation Biology every year at 43 universities. The top three in terms of quality are Columbia University in New York (10 undergraduates annually), Tufts University (18), and the University of Minnesota (2) [3].

Russian universities traditionally teach courses on environmental protection as a whole, without focusing exclusively on the problem of biodiversity conservation. For example, the Moscow State University Nature Protection course at the Department of Geography (Bachelor's degree, 05.03.06, Ecology and Nature Management) primarily focuses on the management side of the nature protection process. It's mandate is, "to introduce the most important features of the formation of nature protection activities in Russia and in the world, to give an idea of the most important forms of territorial nature protection in the modern world, to familiarize with international legal issues of nature protection, to analyze the geographical representativeness of the protected area system", etc. [4]. The Theory and Practice of Nature Conservation (Zapovednoe Delo) discipline (majors 01300 Ecology, 013400 Nature Management) is devoted to territorial nature protection, structure, and functions of protected areas [5].

As a result, there is practically no educational literature or methodological recommendations on Conservation Biology in Russia. The series of Biodiversity Conservation textbooks, published by the MSU Ecocenter in 2002, is in essence the only one in Russian. It includes a translation of the famous "A Primer of Conservation Biology" textbook by Richard Primack [6] as well as three collections devoted to various aspects of studying and preserving biodiversity: geography, monitoring, ecosystem restoration, socioeconomic, and legal foundations.

In 2000, the non-governmental organization Siberian Environmental Center prepared a manuscript translation of a comprehensive textbook for biologists, "Principles of Conservation Biology" by Gary Meffe and Ronald Carroll and contributors. Unfortunately, the translation was not published as a book, but it is available for students and teachers as reference material [7]. A course in Conservation Biology was first tested at NSU in 2017 and, in this format, it was conducted in 2019 and 2020. The purpose of this publication is to present the structure of the Conservation Biology course and the experience of its implementation as a Master's Program at the Novosibirsk State University Department of Natural Sciences.

\section{Methods}

In developing the structure and content of the Course, we used examples from foreign and Russian environmental protection courses, academic literature, as well as personal experience in practical environmental protection, research, and environmental education activities.

The main audience for the Course is NSU Master's students, but the University allows anyone to take the classes. The Course content is primarily presented in lectures. They are supplemented with case studies and an excursion to a specialized scientific institution. In 2019 , the course was conducted in a full-time classroom format and in 2020, due to pandemic restrictions, most classes and tests were held remotely on the Zoom platform.

Special features of the Course include the participation of invited experts who provide a deeper look at specific areas of conservation biology, the use of social networks for more intensive communication with students, and the inclusion of gamification elements in the learning process. In 2020, a new class format was developed and tested in the form of an expert session. At the end of the course, the final exam is conducted in the form of a 
conference (seminar). In addition to the main lecturer, invited experts took part in the assessment of students' knowledge.

\section{Results}

The Conservation Biology discipline (official description on the NSU website [8]) is implemented within the framework of the higher education Novosibirsk State University Master's Program 06.04.01 Biology of the Department of Natural Sciences of (108 hours). The Course awards three credits.

The Program takes into account the international practice of studying and protecting biodiversity and national and regional specifics. The content below is structured by topics (sections) with the number of academic hours and the types of training sessions.

Lectures (24 hours):

1. Global, regional and local environmental problems and conservation biology. Habitat destruction. Climate change and other threats to biodiversity. Conservation biology as a discipline. What is biodiversity? The value of biodiversity.

2. Global biodiversity. Geography of biodiversity and relation to environmental factors. Problems of extinction. Biodiversity assessment. Types of biodiversity. Conservation of populations and communities. The role of key types. Migrations.

3. Interspecific interactions, types of disorders, and invasive forms. Regime of ecosystem disturbances. Ephemera. Grazing and overgrazing. Violation indicator. Habitat fragmentation. Edge effect. Boundaries of communities and ecosystems. Conservation Genetics.

4. Conservation biology and management of protected species and protected areas. Territorial nature protection. Categories of protected areas. Nature protection in the Novosibirsk region: current state and prospects.

5. Conservation biology and management of protected species and protected areas. Territorial nature protection. Categories of protected areas. Nature protection in the Novosibirsk region: current state and prospects.

6. Ecology, politics, and Economics. Ecosystem services.

7. Ex situ species conservation.

8. History of studying the diversity of Siberian vegetation cover. Key botanical territories. Red Books of plants. Botanical collections and protection of rare species. Rare plants in vitro.

9. Restoration Ecology.

Practical exercises (24 hours):

1. Citizen Science. iNaturalist. GBIF. The River of My Childhood documentary. Discussion.

2. Checklist for ecosystem surveys for environmental purposes. Restoring the Ancient Forest documentary. Discussion.

3. Case 1: Orchid Zapovednik nature reserve. (Option: Karakansky Bor nature park)

4. Case 2: Conservation of steppes and grass communities

5. Case 3: Bird protection and monitoring

6. Case 4. Protected area network design

Independent work by students (58 hours):

1. Preparation for practical classes.

2. Completing your portfolio homework.

3. Study of theoretical material that is not covered in lectures.

4. Preparation for the differentiated test. 
In 2020, the participants attended lectures by four invited experts: Ilya Smelyanskiy, Editor-in-Chief of the Bulletin of the Steppe Journal (protection of the steppes, ecosystem services), Elena Kizilova, $\mathrm{PhD}$, Researcher at the Institute of Cytology and genetics SB RAS (conservation of species in situ), Elena Schneider, Independent Researcher (conservation of raptors), Irina Skalaban, Professor of Sociology.

Field excursions to the Central Siberian Botanical Garden of the Siberian Branch of the Russian Academy of Sciences acquainted students with various areas of studying and preserving the diversity of the Siberian plant world. The following is a list of experts, their topics and format: a talk on Rare Plant Species of Siberia with Inessa Selyutina, $\mathrm{PhD}$, an excursion to the Botanical Museum of Siberia with Elena Korolyuk, $\mathrm{PhD}$, an excursion and talk on Creating and Preserving Living Plant Collections with Yuri Ovchinnikov.

In 2020, a class on the Projection of a Nature Park for the Preservation of the Karakansky Bor Pine Forest Ecosystem in an expert session format was developed and tested. Sociologist (Irina Skalaban) and a specialist in the field of protected area planning and design (Ilya Smelyansky) were the featured experts. During the session, participants analyzed the opportunities and consequences of creating a nature park for different stakeholders (local residents, residents of Novosibirsk, authorities, foresters, environmentalists, etc.). In 2019, the course was attended by three NSU students and four non-matriculating students, in 2020, there were 13 NSU students and seven nonmatriculating students, respectively. In 2019, these were only students in the General Biology and Ecology Division. In 2020, the course attracted the attention of students from other divisions in the Department. The composition of students was: Genetics Division five, General Biology and Ecology Division — three, Molecular Biology Division — three, Physiology Division - two.

In 2020, a Conservation Biology working group for course participants (students, lecturers, and other interested people) was organized on the VK social network. [9]. Class materials (presentations, lecture notes, textbooks, reference materials and additional materials) were published there. During the course, elements of gamification were used. Students were asked to portray the most memorable and important moments from the lectures in the form of memes and to post them in the VK group. Emotional reinforcement contributed to better learning and attracted the attention of other students and users of the social network. At the end of the course, an online vote was conducted and the winners received prizes (Field Guide of Western Siberia Birds by Vadim Ryabitsev and Half-Earth by Edward Wilson).

Students had an opportunity to evaluate lesson quality through anonymous voting and at the end of the course with an online questionnaire using Google forms. Questions included (1) impressions of the course as a whole, interest in further study of the subject, and (2) plans to use the acquired knowledge. Of the 15 students who completed the questionnaire, 14 rated the course positively ("useful", "good", "excellent", "informative", "mindexpanding", "maximum teacher friendliness", etc.). More than half of the students want to continue in-depth study of the subject or individual topics. Also, about half of the students expressed their interest in using the acquired knowledge in their research, teaching, and environmental protection activities [10].

To evaluate students, an exam was conducted in the format of an online conference. Each student was provided a case study with questions. The exam included analysis of various sources of information, report preparation, report presentation, and answers to questions. A five-point evaluation scale was used: 100-86 points - excellent (5), 71-85 good (4), 56-70 - satisfactory (3), 55 or less - unsatisfactory (2). Scores from the four teachers were averaged for the final grade. Additional points were added for completing tasks during the semester. The results demonstrated that $38 \%$ of the students had a "good" knowledge of the subject and $62 \%$ acquired an excellent knowledge of the subject. 


\section{Conclusions}

An educated biologist should see "ecology and evolution" through the lens of a new reality. Man in the Anthropocene epoch became the geological force of the planet. In this sense, Conservation Biology is an important part of higher education for biologists in the midst of the current biosphere crisis.

Implementing a Master's Degree course at the NSU Department of Natural Sciences has proven the relevance of this discipline for students. The combination of auditorium and online forms of teaching, opportunities provided by social networks, elements of gamification, discussions and excursions, and involvement of expert practitioners facilitated impressive student achievement in mastering the necessary knowledge and skills. It also motivated the students to pursue further studies in the subject and seek applications in their research and other practical activities.

Given the importance of biological diversity conservation, a further step in the right direction is to increase the number of students who are familiar with the main approaches to Conservation Biology and to consolidate the theory into practice. This can be done by expanding the course so the discipline is included as a mandatory Master's Degree subject and/or a similar course is developed for the Bachelor's Degree, and a summer workshop on the subject is introduced.

Acknowledgements. I would like to sincerely thank Professor Mikhail Sergeev, without his participation this course would not have taken place, my colleagues who participated in the course as experienced practitioners, and also arranged a wonderful thematic immersion in the world of plant diversity and Siberian botany. My special thanks to Sarah LindemanKomarova for editing and proofreading the English version of the text. I also want to note the curiosity and perseverance of the students who attended the course. You guys inspire me to continue this story.

\section{References}

1. J. Douglas, Nature, 275 (1978)

2. R. Noss, Ecography 22(2) (1999)

3. https://www.universities.com/programs/conservation-biology-degrees

4. The program of discipline "Nature Conservation" (Moscow, Moscow State University, 2019)

5. Theory and practice of nature reserve management. Software and methodological complex (Nizhny Novgorod, NSTTU, 2005)

6. R. B. Primak, Fundamentals of Biodiversity Conservation (Moscow, Publishing House of Scientific and Educational-Methodological Center, 2002)

7. Martha J. Groom, Gary K. Meffe, C. Ronald Carroll, Principles of Conservation Biology (Sinauer Associates. Sunderland, MA, 1997 https://gislab.info/forum/viewtopic.php?t=14196

8. RAP Environmental biology. Working programm. Electronic archive of NSU (Novosibirsk, 2020) https://lib.nsu.ru/xmlui/handle/nsu/18179

9. Working group of course participants «Conservation biology», FEN NSU course https://vk.com/biodivconsclass

10. Final questionnaire of the student of the course "Environmental Biology" https://docs.google.com/spreadsheets/d/1Yc4Ibs0LLFFiQOJmPi3 S9xFrPmEVHtob4MnaFb6es/edit?usp=sharing) 